Journal of Computer Science 7 (6): 902-908, 2011

ISSN 1549-3636

(C) 2011 Science Publications

\title{
Creating a GIS Application for Retail Facilities Planning in Jeddah City
}

\author{
Abdulkader A. Murad \\ Department of Urban and Regional Planning, \\ Faculty of Environmental Design, King Abdulaziz University, \\ PO Box 80210, Jeddah-21589, Saudi Arabia
}

\begin{abstract}
Problem statement: The aim of this study is to create a GIS application for retail facilities planning in Saudi Arabia. Jeddah city has been selected as a case study representing a major commercial city in Saudi Arabia. Approach: The crated application covers several retail planning analysis issues. These issues are divided in to two major groups called the city scale retail planning and the retail center market area. The former covers defining the location and the distribution of all retail centers in Jeddah city and classifying retail centers based on size and area. Meanwhile, the latter includes defining the spatial distribution of retail demand of selected centers and identifying the primary catchment area of the selected retail centers. In order to build this application, a survey is made for selected retail demand and GIS address geocoding function is used to convert the address data of retail demand into points features. In addition, GIS network analysis is used in this application to produce drive time based trade areas for the selected retail centers. Results: Retail centers were classified in Jeddah city as three groups called small centers (has less than 100 shops), medium centers (has 100-200 shops) and large centers (has more than 200 shops). Conclusion: Based on this application, retail planner in Jeddah city can easily identify the pattern and trends of all retail centers in Jeddah city. The created application can be used by retail planners in Jeddah city for evaluating retail market and for identifying market segments that the retail centers are under-serving.
\end{abstract}

Key words: Geographical Information Systems (GIS), retail centers, market area, spatial statistic, standard deviation ellipse, micro scale, data sets, novel technology

\section{INTRODUCTION}

Geographical Information Systems (GIS) are used today to provide advanced analysis tools and complete data packages for analyzing retail and demographic information. These tolls help retail planners in taking important retail planning decisions such as choosing retail locations, identifying and reaching potential customers, finding new markets, performing customer or store prospecting, defining customer-based or store trade areas and identifying best retail locations.

Cheng et al. (2007) pointed that GIS technology is appropriate for a variety of usages including resource management, land surveying and business planning. For example, a GIS might allow planners to create maps for specific use, while another GIS might be able to determine the size of wetlands necessary to be protected against damages and pollution from new district development. The way that maps and other data have been stored or filed as layers of information in a GIS makes it possible to perform complex analyses. Even if image data that have already been converted from paper to digital form are not available, a GIS can produce digital maps by incorporating spatial data. Tabular data, such as shoppers' behavior obtained by means of surveys, are then entered into it to act as the information for different layers (Cheng et al., 2007).

Nasirin and Birks 2003, added that GIS have rapidly developed as input to decision support systems (DSS) employed by retailers and have become vital to support decisions made retailers for both operational day-to-day such as sales promotion activities and long-term strategic decision-making.

The use of GIS has come of age as a result of several interrelated factors. First, there are many GIS software products that are available from commercial vendors and universities. Second, computer workstations are now capable of handling many of the computational, retrieval and storage problems within a reasonable amount of time and at reasonable cost. Third, graphical displays and plotters are now sophisticated and fast, producing high-quality and highresolution output. Fourth, geographic data vendors as well as governmental agencies such as the Bureau of the Census of the US Government have made large amounts of geographic data available at reasonable 
cost. Fifth, the use of remote sensing has expanded, especially in environmental monitoring and this has led to the need for systems that are capable of handling large amounts of data as well as serve as a major source of land coverage information. Sixth, the emergence of the satellite based Global Positioning System (GPS) has made it easy to collect attribute data along with its location at relatively low cost and with relatively high accuracy. Each of these factors has contributed to the growth of the GIS industry. Nasirin and Birks, 2003 added that the availability of geodemographic datasets at a national level, for example, in the UK, the National Readership Survey (NRS), is also a major factor in changing retailers' desires to utilize GIS.

Today, Geographical Information Systems (GIS) are used at several planning applications including land use planning (Eldarndaly, 2009), health care planning, environmental planning (Saberioon et al., 2010), forest planning (Hasmadi et al., 2010) landscape planning (Elhadi et al., 2009; Andrea, 2010; Saberioon et al., 2010; Jusoff, 2010; Solaimani et al., 2009; Jalloh et al., 2009) and water planning ( Tung et al., 2009; Maio et al., 2010; Keita et al., 2009). Retail planning is considered as one of the planning fields that could benefit from using this novel technology. Retail planners are faced today with many issues that can be better handled with GIS. These include constructing demographic, sales and competitive analysis, finding the best locations for new retail stores, creating effective marketing campaigns (Olson et al., 2005) , scheduling and route deliveries (Ganesh and Narendran, 2005) and providing better customer care information system (Razmi et al, 2006). Today, GIS can be used for retail planning applications to answer the flowing analytical questions: Where to open new store?, Which stores are under performance?, What is the market share and penetration?, How many potential customers live within 10 miles of the store?, How many competitors are located within the market area of the store? and Where should a new store be located in order to minimize the impact it has on the current location of stores? (Murad, 2007).

The diffusion of GIS in retail organizations can be traced to a number of factors relating to supply and demand of retail services. The demand factors include location of retail stores and maximizing profitability. Meanwhile, the supply factors are related to location of competitors and the visualization of consumer behavior.

The most common retail GIS applications include customer spotting, trade area analysis (e.g., demographic reporting for given trade areas), customer profiling, competitor analysis, hot-spotting, sales forecasting and consumer behavior modeling. These can be applied to a number of decision events, from relatively low-risk store openings, renovations and merchandising decisions to major high-risk decisions, such as, corporate acquisition of competing chains or international expansion through merger activities (Hernandez, 2007).

GIS application in retail field is acknowledged and used by several international retailers. For example, Murad (2009), has pointed that GIS functions such as Buffer and Thiessen can be used in retail planning field for catchment area definition. Maatta-Juntunen et al. (2011), have discussed a GIS application for measuring retail location accessibility in Finland and utilize GIS tools to assess store locations in terms of $\mathrm{CO} 2$ emissions from private cars used for consumer traffic. Birkin (1996) have used GIS to study changes in market penetrations for a new retail store and showed how GIS is used to find out the opportunities for locating new store at the South coast of England at the town of Hastings. This example indicates that the analysis of market penetration is one of the main retail analysis that can be made using GIS. Murad (2003) have presented similar GIS application that calculates market penetration for two retail centers at Jeddah Saudi Arabia. The results of such study indicate that there are areas of good and poor performance and pointed that shopping developers can use those results to try to attract more customers from areas with low performance.

The use of GIS in modeling demand flows to retail location is another very important retail issue. Here, GIS is used together with spatial interaction models to calculate the interaction between retail location and residential areas. (Suarez-Vega et al., 2011; Murad, 2003; Birkin, 1996; Bullas and Clarke, 2000).

In a summary, It can be said that GIS is applied at several retail studies and these studies varies from defining retail territories and analyzing market penetrations up to modeling the flows of the retail demand. This study will discuss how to use GIS for retail facility planning in Jeddah city, Saudi Arabia.

\section{MATERIALS AND METHODS}

The created application covers macro and micro scale retail planning issues. The formers covers evaluation the location of retail centers. Meanwhile, the latter is focused on one selected retail centers called $\mathrm{Al}$ Hijaz Center and covers indentifying and analyzing the market area of retail center. In order to build this application, several data sets were captured and built using ArcGIS software. These are as following.

On-screen digitizing and address geo-coding functions were used for capturing the required data. Road network and city districts data were entered in the geo-database using on-screen digitizing. Meanwhile, 
locations of retail centers are created for the presented application using address geo-coding function. Both of these two GIS functions produce vector data models (points, lines and polygons). The created geo-database covers spatial and non-spatial retail data. The former, covers the exact location of retail centers in the city. The latter, includes retail center capacity (GLA), car parking size, amount of customers and many other useful information for describing the characteristics of existing retail centers. To build this geo-database, several data sets were collected and captured into ArcGIS software. The collected data are classified as points, lines and polygons features. The exact location of retail centers is modeled in the GIS as points features. Road network and city districts data were built in the GIS as lines and polygon fetuses. For each of these features the relevant attributes were linked at the feature attribute table.

One of the prime objectives of this application is to define retail market based on real demand locations. Accordingly, a survey was made on a sample of 500 retail customers which aimed at defining the spatial distribution of selected retail customers. Their locations were converted in the GIS as point features with a city district resolution. In addition, the exact location of retail centers are modeled in the GIS as points features. In addition to making point features, the present application created polygon features showing city district boundaries as well as line features showing city road network. These two basic GIS features were used with point data to define and model the market area of retail centers at Jeddah city. For each of these features the relevant attributes were linked at the feature attribute table.

\section{RESULTS AND DISCUSSION}

Classifying of retail centers: In order to evaluate the location of retail centers in Jeddah city, GIS simple and advanced functions were used for defining the spatial distribution of retail centers and for defining the growth direction of retail centers in Jeddah city. Retail centers in Jeddah city can by classified based on different attribute data such as center name, land area, GLA and parking size. These data were collected and saved in the geo-database and can be used for identifying the characteristics of retail centers in Jeddah city. Using the graduated symbol function of ArcGIS software, retail centers in Jeddah city were classified and the results of this type of analysis are shown in Fig. 1. Looking at this figure retail planner can easily identify the location of large or small centers. Drawing quantities by graduated symbols is considered as an effective way to visually present a numeric attribute. This method is suitable for numeric data that represents a rank or progression of values. It draws larger symbols first and smaller symbols afterward. This is so that features with large values do not obscure features with smaller values. The graduated symbols method is used to map discrete locations or lines. Accordingly, graduated point symbols are drawn as the locations of individual features to show the magnitude of the data value. Based on the results of this function, retail centers could be classified as three groups called small centers (has less than 100 shops), medium centers (has 100-200 shops) and large centers ( has more than 200 shops). This type of GIS classification tool can also be used with multiple attributes such as comparing retail center size with car parking area. This type of comparison can identify retail centers that has large amount of shops but not providing enough car parking area for retail demand.

Modeling the direction of retail growth: Measuring orientation and direction of retail centers help retail planners in abstracting the spatial trends in the distribution of retail centers. GIS spatial statistic functions can be used to measure whether-and to what extent- the distribution of features crates a pattern. The resulted direction of pattern can be used for several purposes. For example; one can calculate the degree to which student test scores in a city are clustered. Another example is found in the application of regional transportation network where planners need to identify the direction of manufacturing, retail and financial activities. In another example retail planner might want to use this function to see whether different types of businesses such as financial and manufacturing have similar trends or corridors in the city.

GIS spatial statistic tools can define the direction and orientation of points, polygons and lines features. For the presented application, points features showing retail centers location are selected and used within ArcGIS spatial statistical tools to define the orientation of retail centers in Jeddah city. The result of this type of analysis is presented in the form of an ellipse shape. It is produced by calculating standard distance in the $\mathrm{x}$ and $y$ directions and by defining the axes of an ellipse encompassing the distribution of features. The ellipse is referred to as the standard deviation ellipse which allows the analyst to see if the distribution of features is elongated and hence has a particular orientation.

The standard deviation ellipse measures the standard deviation of the features from the mean center separately for the $\mathrm{x}$-coordinates and the $\mathrm{y}$ coordinates. The length of the ellipse axes are calculated in the east-west ( $\mathrm{x}$ - axis) and northsouth (y-axis) directions in distance unites (meters). 


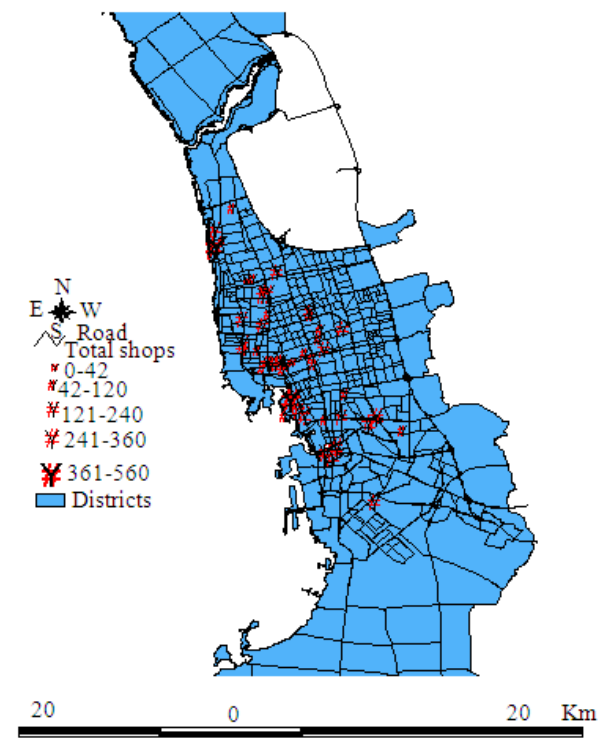

Fig. 1:Classification of Retail centers based on number of shops in each center

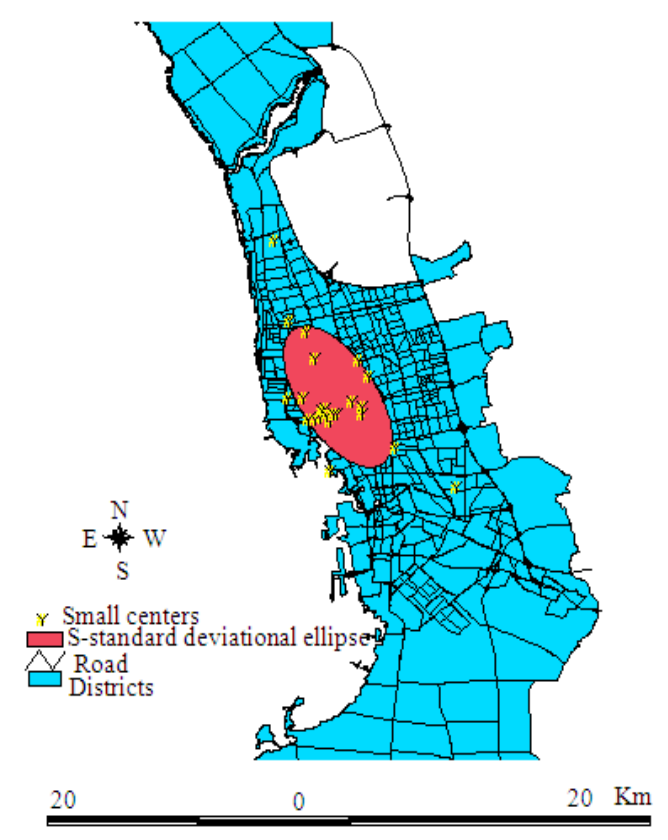

Fig. 2: Standard deviational ellipse for small retail centers in Jeddah city

Since the standard deviation is measured in each direction from the mean center, the total length of each axis is twice its standard deviation (ibid).

The presented study has calculated the standard deviation ellipse for every retail center group (large, medium and small). The resulted ellipse for small retail centers are shown in Fig. 2. Based on this result retail planner can easily identify the pattern and trends of all retail centers in Jeddah city. It is clear that orientation of retail growth in Jeddah city is toward the northern city districts and accordingly, any future retail development should follow this direction for the purpose of attracting large retail demand. Alshatee and Almohamdia are two districts located north of the city are considered to be the potential location for any future retail development in Jeddah city.

Defining retail market area: One important question always asked by a retail planning officer deals with retail-market area definition. This answer depends on the analysis method or technique used for this purpose. For a GIS-based analysis research, retailers can define the following types of market areas around the service locations: (a) Simple ring: created around stores using a specified radius, (b) Data-drives ring: created around stores using radius proportional to a store characteristics such as total sales, square footage and Grass Leasable Area (GLA), (c) Equal competition: creates trade area boundaries halfway between each store an its neighboring stores (Thiessen polygons), (d) Drive time: defines areas accessible along the street network based on specified maximum travel time or distance, (e) Gravity model: predicts the sales potential of an area based on distance, competition, attractiveness factors and consumer spending and (f) Threshold ring: creates rings containing a specified population or household count (ESRI, 2009).

Looking at the various types of GIS-based market area definition techniques, the present study selected the simple ring method and then added to it a location of retail demand. Accordingly, the first step to produce this output was to plot and map the locations of retail customers that were interviewed in the course of this study. One of the useful GIS functions to be used for this purpose is known as Address Geocoding. It refers to the process of creating map features from addresses, place names, or similar information (Ormsby et al., 2004). In order to use this function, ArcGIS software requires that the user should have an address table containing a list of addresses stored as a data-base table or a text file as well as a set of reference data such as streets on which the addresses can be located. Using city-district shape file as a reference data and address table of retail customers, the presented application has produced point features describing the spatial distribution of retail customers of one selected retail center in Jeddah city (Fig. 3). 


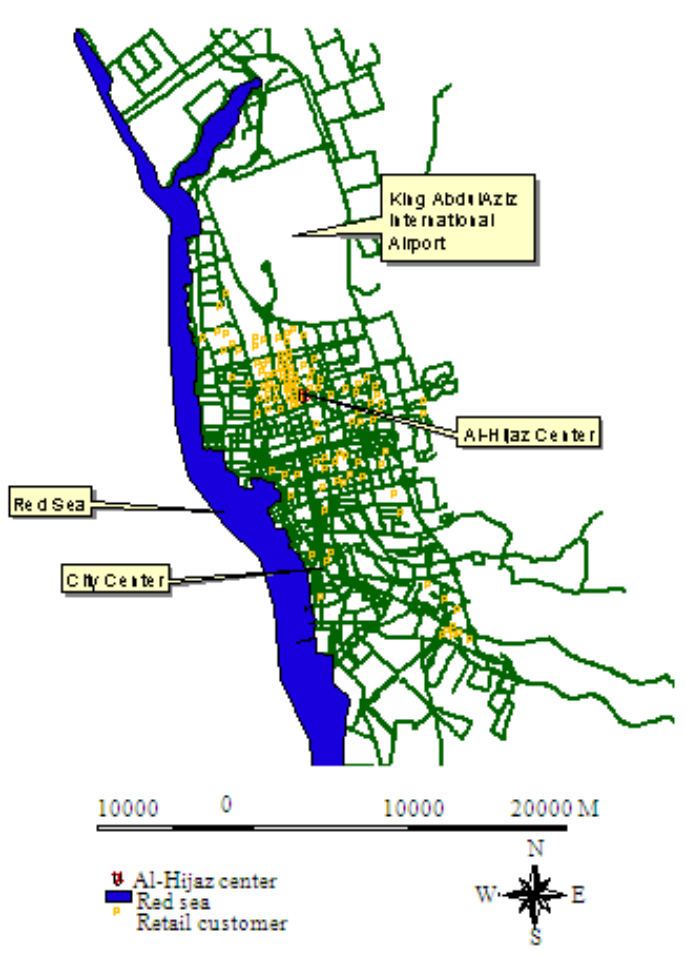

Fig. 3: Distribution of retail customers

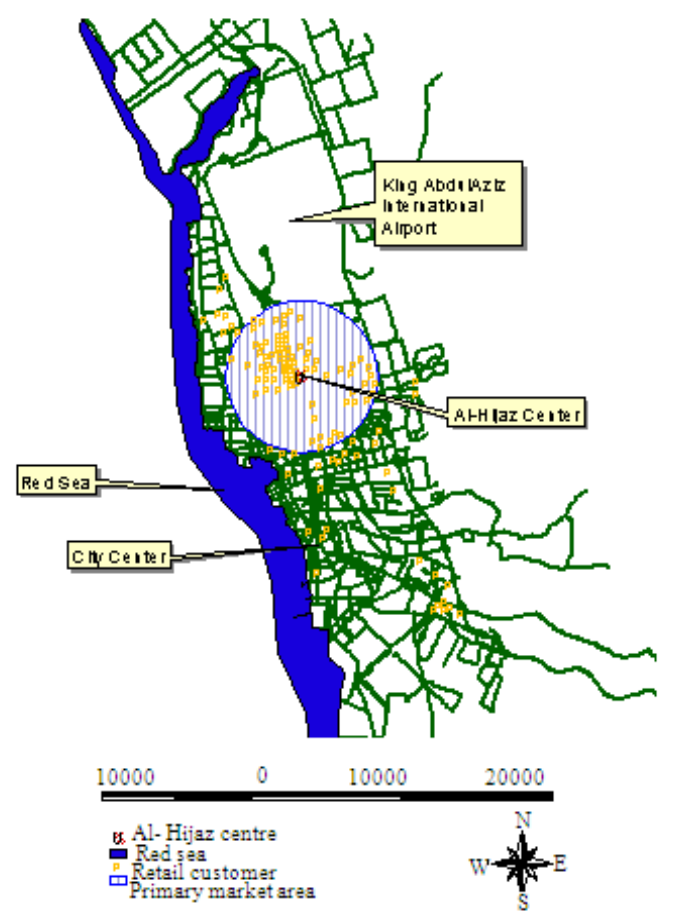

Fig. 4: Primary market area of al-Hijaz retail center
This output shows the dissemination of the market area of the selected center. It is evident that there are some parts of the city (Al Bawadi, Al-Rabwah and AlSalamah) which produce remarkable retail customers to this center. These areas are actually falling within the 5$\mathrm{km}$ ring defined around the selected center (Fig. 4). This output forms the primary market area of Al Hijaz Center and can be used by retail developers to define the parts of the city providing a larger amount of customers to this center. These parts should always be monitored and evaluated by retailers to make sure that these already attracted customers are regularly visiting this center.

Market area analysis: This part of the study discusses how GIS can be applied to meet the objective of expanding the existing retail market. There are several GIS-based techniques to be used by retailers for preparing policies in this respect. One of them is based on drive-time analysis demonstrated by the present application. ArcGIS software is applied to create market areas based on drive-time bands. In order to make these drive bands $(0-10,10-20,20-30$ and 30-40 min.), data about road speed were captured into the road network attribute table and used to produce these drive time-based market areas. Customer locations' data were overlaid with the resulted drive-time bands to analyze these locations according to their nearness to the chosen center (Fig. 5). A key finding of this analysis is that there are different amounts of customers visiting Al-Hijaz center according to the drive-time bands. In order to classify these customers, GIS overlay functions are used to subdivide each customer location according to its localization within the drive-time band. This type of GIS functions is defined as the process of comparing spatial features in two or more map layers (Grimshaw, 2000). GIS applied the input coverage and the overlay one to produce output coverage based on selected logic Boolean functions which can be used by different applications. They are the following: intersect, not intersect, union, all but A or B, union levels and A not B (Davis, 1996). This part of the application deals with the intersect function demonstrating only the portion of the input coverage that falls inside the intersect one. Here an input coverage is the location of all the retail customers and an intersect coverage is the resulted drive-time band pattern. If the input coverage is a point one, as in our case, the intersect function will result in an output coverage of point feature, too (Chou, 1997). 


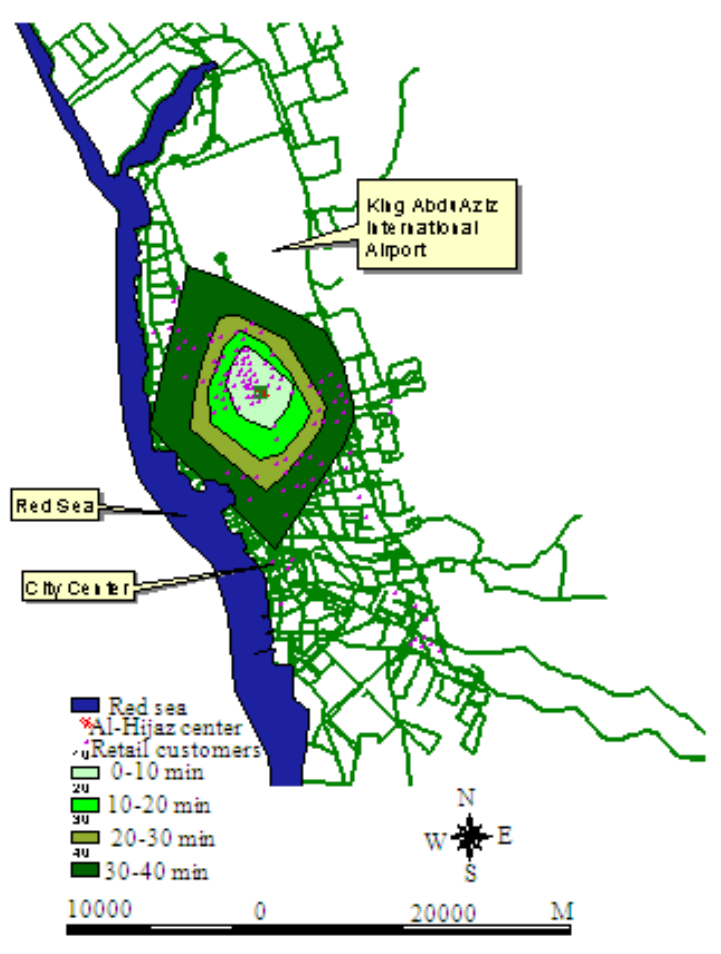

Fig. 5: Drive Time Market Area

This output is useful for retail planners as it defines the extent of the retail market. Besides it can be applied to advise retail managers concerning the locations where no desired size of customers is produced and accordingly, to focus on these locations and try to expand the already existing retail market to cover such less attracted areas. For this retail center, city districts such as Al-Mohamadia, Al-Aziziayah, Al-Safa and AlAndalus are located within the less attracted bands. Therefore, retail managers should approach these districts more closely and introduce their center goods and services to people living in such areas so that they could be more attracted to this center.

\section{CONCLUSION}

GIS is considered as useful and important analytical tool in many retail planning applications such as market penetration, business forecast, consumer behavior/profile tracking and prediction. The current study presents a GIS application for defining the spatial distribution of retail centers in Jeddah city. The application classify retail centers based on shopping sizes and produce three types of retail centers named as large, medium and small centers. For each of these three centers types, GIS spatial statistics are calculated. In addition, This study discusses how GIS could be implemented as a tool for defining and analyzing the retail market of Al-Hijaz Center in Jeddah city based on customer location. Finally, a market area investigation has been performed based on GIS drive-time analysis technique and by using GIS overlay analysis function. This methodology could help retail planners in defining both strongly and less attracted parts of Jeddah city. The results of the created GIS application are considered as valuable tools for increasing the efficiency of retail center management and for evaluating the performance dynamics of retail center. The created application can be used by any retail center managers in Jeddah city for evaluating retail market and for identifying market segments that the retail center is under-serving

\section{REFERANCES}

Andrea, F., G. Andrea and M. Giuseppe, 2010. Rock slopes failure susceptibility analysis: From remote sensing measurements to geographic information system raster modules. Am. J. Environ. Sci., 6: 489-494. DOI: 10.3844/ajessp.2010.489.494

Birkin, M., 1996. Intelligent GIS: Location Decisions and Strategic Planning. 1st Edn., GeoInformtion International, New York, ISBN-10: 0470236140, pp: 292.

Bullas, D. and G. Clarke, 2000. GIS and microsimulation for local labour market analysis. Comput. Environ. Urban Syst. 24: 305-330. DOI: 10.1016/S0198-9715(99)00051-4

Cheng, E.W.L., H. Li and L. Yu, 2007. A GIS approach to shopping mall location selection. Build. Environ., $\quad 42$ : 884-892. DOI: 10.1016/J.BUILDENV.2005.10.010

Chou, Y.H., 1997. Exploring Spatial Analysis in Geographic Information Systems. 1st Edn., Onward Press, USA., ISBN-10: 1566901197, pp: 474.

Davis, B.E., 1996. GIS: A Visual Approach. 2nd Edn., Cengage Learning, Canda, ISBN-10: 076682764X, pp: 438.

Eldarndaly, K.A., 2009. Integrating gene expression programming and geographic information systems for solving a multi site land use allocation problem. Am. J. Applied Sci. 6: 1021-1027. DOI: 10.3844/ajassp.2009.1021.1027

Elhadi, E.M., N. Zomrawi and H. Guangdao, 2009. Landscape change and sandy desertification monitoring and assessment. Am. J. Environ. Sci. 5: 633-638. DOI: 10.3844/ajessp.2009.633.638 
ESRI, 2009. ArcGIS® 9.3 Geocoding Technology, ESRI, Redlands. http://www.esri.com/library/whitepapers/pdfs/arcgi s93-geocoding-technology.pdf

Ganesh, K. and T.T. Narendran, 2005. CLOSE: A heuristic to solve a precedence-constrained travelling salesman problem with delivery and pickup. Int. J. Services Operat. Manage. 1: 320-343. DOI: 10.1504/IJSOM.2005.007496

Grimshaw, D.J., 2000. Bringing Geographical Information Systems into Business. 2nd Edn., John Wiley and Sons, New York, ISBN-10: 0471333425, pp: 346.

Hasmadi, I.M, H.Z. Pakhriazad and F.S. Mohamad, 2010. Geographic information system-allocation model for forest path: A case study in Ayer Hitam forest reserve, Malaysia. Am. J. Applied Sci., 7: 376-380. DOI: 10.3844/ajassp.2010.376.380

Hernandez, T., 2007. Enhancing retail location decision support: The development and application of geovisualization, J. Retail. Consumer Serv., 14: 249-258.

DOI: 10.1016/J.JRETCONSER.2006.07.006

Jalloh, M.B., W.S.W. Harun, J. Talib and O.H. Ahmed, 2009. A simulation model estimates of the intercropping advantage of an immature-rubber, banana and pineapple system. Am. J. Agric. Biol. Sci., 4 : 249-254. DOI: 10.3844/ajabssp.2009.249.254

Jusoff, K., 2010. A new approach in individual tree counting of Nyatoh (Palaquium spp.) using an airborne spectroradiometer. Am. J. Applied Sci., 7: 486-492. DOI: 10.3844/ajassp.2010.486.492

Keita, S., Z. Tang, S. Dong and Y. Jiang, 2009. Evaluation of some organic pollutants transport into the shallow groundwater and surface water of Jiaxing Landfill Area. Am. J. Applied Sci., 6: 2010-2017. DOI: 10.3844/ajassp.2009.2010.2017

Maatta-Juntunen, H, H. Antikainen, K. Ossi and J. Rusanen, 2011. Using GIS tools to estimate CO2 emissions related to the accessibility of large retail stores in the Oulu region, Finland. J. Transport Geography, 19: 346-354.

Maio, M.D., F. Minucci and G. Nocerino, 2010. Evaluation of the groundwater global pollution risk: Relationships with territorial planning. Am. J. Environ. Sci., 6: 103-114. DOI: 10.3844/ajessp.2010.103.114
Murad, A.A., 2003. Creating a GIS application for retail centers in Jeddah city. Int. J. Applied Earth Obser. Geoinform., 4: 329-338. DOI: 10.1016/S0303-2434(03)00020-5

Murad, A.A., 2007. Using GIS for retail planning in Jeddah city. Am. J. Applied Sci. 4: 821-827. DOI: 10.3844/ajassp.2007.821.827

Murad, A.A., 2009. Using customers data for defining retail market size: A GIS Approach. Int. J. Bus. Inform. Syst., 4: 340-359. DOI: 10.1504/IJBIS.2009.024100

Olson, D.L., B. Chae and C. Sheu, 2005. Issues in multinational ERP implementation. Int. J. Services Operat. Manage., 1: 7-21.

Ormsby, T., E. Napoleon, R. Burke, L. Feaster and C. Groessle, 2004. Getting to know ArcGIS desktop: The Basics of ArcView, ArcEditor, and ArcInfo Updated for ArcGIS 9, 2nd Edn., ESRI, Inc., USA., ISBN-10: 158948083X, pp: 588.

Razmi, J., M. Zairi and A. Gunasekaran , 2006.The application of analytic hierarchy process in classification of material planning and control systems. Int. J. Services Operat. Manage., 2: 352-366.

Saberioon, M.M., M. Mardan, L. Nordin, M.S. Alias and A. Gholizadeh, 2010. Predict location(s) of Apis dorsata nesting sites using remote sensing and geographic information system in melaleuca foresti. Am. J. Applied Sci., 7: 252-259. DOI: 10.3844/ajassp.2010.252.259

Solaimani, K., S. Modallaldoust and S. Lotfi, 2009. Soil erosion prediction based on land use changes (a case in Neka watershed). Am. J. Agric. Biol. Sci., 4: 97-104. DOI: 10.3844/ajabssp.2009.97.104

Suarez-Vega, R., D.R. Santos-Penate, P. DortaGonzalez and M. Rodriguez-Diaz, 2011. A multicriteria GIS based procedure to solve a network competitive location problem. Applied Geography, 31: 282-291. DOI: 10.1016/J.APGEOG.2010.06.002

Tung, P.G.A., M.K. Yusoff, N.M. Majid, G.K. Joo and G.H. Huang, 2009. Effect of $\mathrm{N}$ and $\mathrm{K}$ fertilizers on nutrient leaching and groundwater quality under mature oil palm in sabah during the monsoon period, Am. J. Applied Sci., 6: 1788-1799. DOI: 10.3844/ajassp.2009.1788.1799 